\title{
No-Stop Shopping City: Supermarkets, Hybrid Space, and the Logistics of the Quotidian
}

\author{
NEREA FELIZ \\ University of Texas at Austin
}

Lock up a department store today, open the door after a hundred years and you will have a museum of art.

-Andy Warhol

Archizoom Associati's 1970s dystopian “No-stop City” manifesto affirmed: "Architecture no longer represents the system, it is the system...Production and consumption poses one and the same ideology, which is that of programming." ${ }^{1}$ No-stop City portrayed the future of the capitalist metropolis as an endless supermarketslash factoryinteriorspace where production and consumption coalesced into a singular and infinite isotropic field. With the digitalization of consumption, Archizoom's dystopic overlap of production and consumption is already a reality. How is endless space framed and created by the digitizing economic realities of the 21st century? We are beginning to see $a$ transition in which retailers are attempting to merge the experience of online and offline shopping, creating a new hybrid marketplace. How is this transition taking place?

\section{INTRODUCTION, A MATTER OF FLOW}

Commerce has always been one of the most common means by which we experience public activity. The Greek agora and the Roman forum were marketplaces as well as primary centers of civic engagement at the heart of the city. The configuration of the market emerged directly from the urban fabric of the host environment; its transformation, is deeply rooted in changing modes of transportation, city demographics, patterns of urban growth and political and economic forces. Commerce engages a network of flows and exchanges among vendors and the public, including goods, information and capital, while involving profound social and cultural needs and desires. These complex relations constitute a variable organic system hosted at the site of the market. The history of market places is intrinsically linked to the history of cities. Trade routes determined the location of cities and vice versa. The city's reason for existence was the market, which the rural areas didn't have and didn't need. As Max Weber pointed out: to be considered a city in the economic sense, there must be a local market at which the local population fulfills the majority of its daily needs. ${ }^{2}$ The ancient market was always located at the lowest point of the city, as if everything should naturally flow to it. Today, the speed of the flow of commodities is unprecedented. Technological innovation, transportation advances and globalization have gradually challenged and transformed this typology, resulting in the contemporary supermarket: a systematically optimized spatial product of logistics driven design. ${ }^{3}$
The supermarket, the stomach of the city, is a quintessential part of the global contemporary quotidian. Ubiquitous and extraordinarily familiar, a typical supermarket today is 41,300 square feet and carries around 42,000 products. ${ }^{4}$ Supermarkets operate within global infrastructural networks as containers and conduits of both people and merchandise $^{5}$ : Kiwis from New Zealand, strawberries from Mexico and tomatoes from the Netherlands etc. Supermarkets host an exceptional concentration of biodiversity that cannot be paralleled by the natural world. Behind their layout and their shelving distribution there is what food marketing specialist Michael Moss describes as a "fiercely competitive industry, fighting for stomach share" with profound repercussions at a global scale. Triggering the expedited supply of goods from producers, to retailers, to consumers, the design of this engineered landscape of perishable goods continues to evolve fueled by the digitizing economic realities of the 21st century. This paper looks at some of the latest transformations disrupting the contemporary supermarket as we know it, derived from the application of new digital instrumentalities. Instead of looking at the territorial implications of trade flows and supply chains, the collection of case studies in this paper addresses some of the changes informing contemporary shopping practices and the space of the supermarket. Considering the technological and logistical optimization of the supermarket from the inside-out, both online and offline, this paper's selection of recent implementations, attempts to provide a glimpse at the multifaceted transformation of the consumers experience of grocery shopping and the emergence of a new hybrid marketplace, that is both physical and virtual.

\section{NO-STOP SHOPPING CITY}

Walter Benjamin described strolling, selecting, purchasing and consuming as an activity determining modern life. Today, those same activities take place online. The contemporary flaneur strolls through social media, encounters commodities, compares product reviews, analyzes prizes, selects, purchases and consumes online. Online browsing, the selection and purchase of commodities, is one of the defining activities of the present flaneur. In fact, indulging in this form of consumption is a big part of contemporary "leisure" time. The new flaneur is always connected in a state that blurs work, life, and shopping, private and public time. The physical store is no longer the only shopping space. In the emerging hybrid marketplace, retailers operate both online and offline, tracking our shopping habits and using targeted advertising to influence our behavior. 


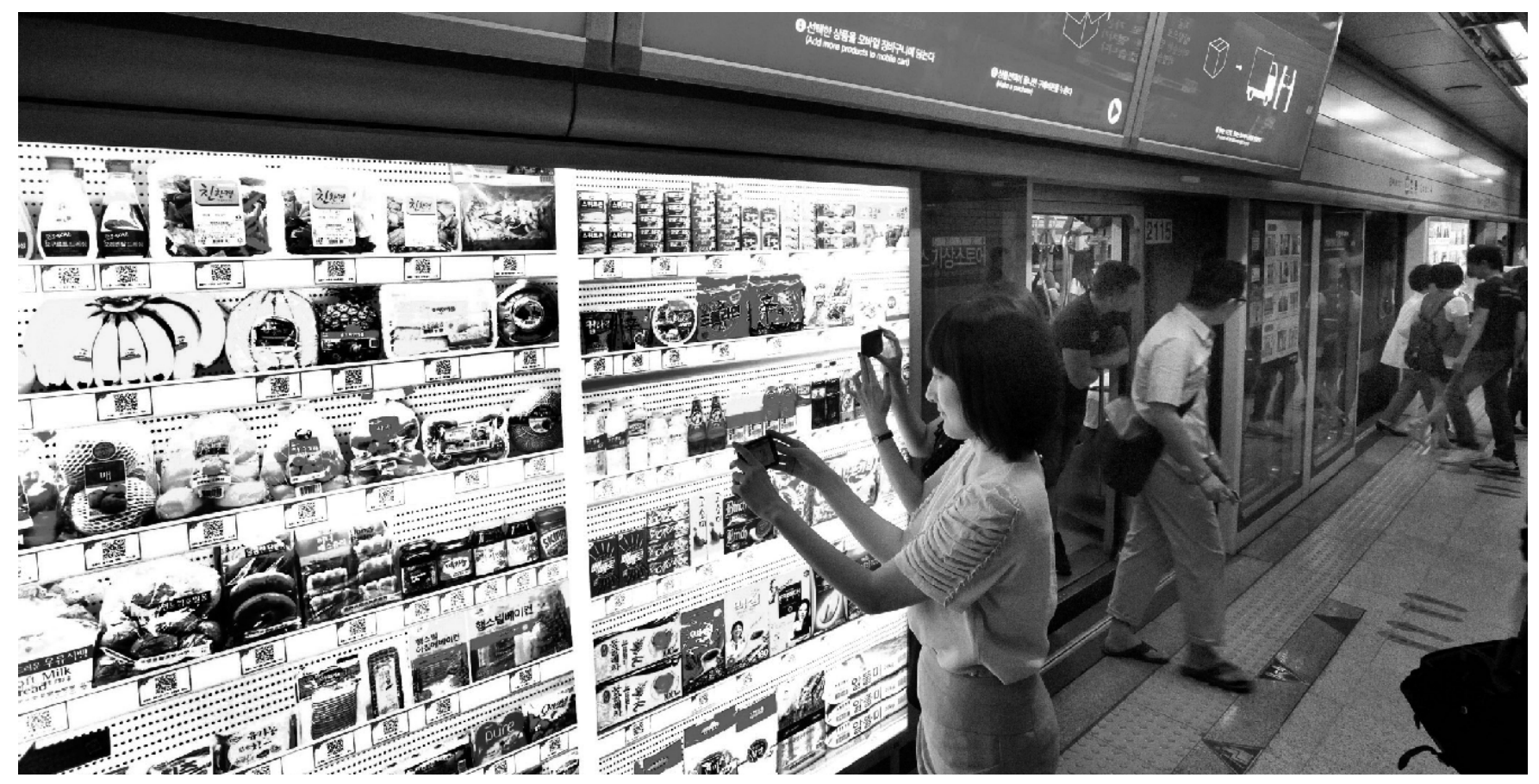

Figure 1: Tesco Homeplus virtual storefront, South Korea, from Tesco PCL.

Archizoom Associati's 1970s dystopian "No-Stop City" manifesto affirmed: "Architecture no longer represents the system, it is the system" "...Production and consumption poses one and the same ideology, which is that of programming." ${ }^{6}$ No-Stop City portrayed the future of the capitalist metropolis as an endless supermarket slash factory, an interior space where production and consumption coalesced into a singular and infinite isotropic field. Against Archizoom's auguries, actual production continues to be, in most cases, an increasingly remote condition. However, with the digitalization of consumption, Archizoom's dystopic overlap of production and consumption is already a reality. Online retail makes consumption ubiquitous. The publication of the Harvard Design School Guide to Shopping, in 2001, manifested how shopping was physically intruding all other institutions and programs. The Barcelona Pavilion, the airport and the museum were already performing as shopping malls. ${ }^{7}$ Currently, shopping is becoming a state of mind. It can take place anywhere with an internet connection. How is endless shopping space framed and created by the digitizing economic realities of 21 st century?

\section{AUGMENTED SHOPPING, PHYSICAL SPACE MEETS VIRTUAL SPACE}

As Koolhaas already predicted, retail's perpetual reinvention in order to sustain consumer activity inevitably expanded to virtual space. ${ }^{8}$ As new technologies disrupted our understanding of sensory experience, material logics, and production networks, even food industry retailers are beginning to participate in the new hybrid marketplace by combining physical and virtual space. Ironically, the first attempts in augmented grocery shopping relied on analog reproductions imitating the Fordist logic of the brick and mortar supermarket. In 2011 South Korea's Tesco branch "Home Plus" opened virtual supermarkets in a number of subway stations in Seoul. A series of billboards illustrating real scale images of edible products covered the walls of mass transit stations. Customers could browse the "aisles," scan bar codes with their smart phones, and have groceries delivered directly to their homes. "Waiting time becomes shopping time" explains Tesco's promotional video. ${ }^{9}$ In 2012 Tesco tried the system at Gatwick's North terminal: travelers could do their grocery shopping while waiting in the departures lounge and schedule to receive the groceries at home after their vacation. ${ }^{10}$ Also in 2012, Chinese supermarket giant Yihaodian announced plans to launch 1000 augmented reality supermarkets to be located in parks and a number of landmarks in major cities across China. ${ }^{11}$ The same year, Peapod introduced virtual grocery markets at transit stations in Philadelphia. ${ }^{12}$ As online shopping became increasingly commonplace these early experiments relying on analog billboards to encourage online sales were soon obsolete. Why rely on analog billboards to attract customers when you can contact them personally through their devices?

Augmented shopping today is making consumerism more convenient and persuasive by communicating directly to customers and influencing consumer behavior on the spot. Using Bluetooth-enabled "beacons" that communicate with installed apps, stores can trigger alerts on shopper's smartphones as they pass certain locations. ${ }^{13}$ Shoppers might receive alerts for sales or specials when passing items 
in a store, or even be greeted with messages when physically approaching a store. The power of these "beacons" to impact consumers conduct in real time can affect the way customers move through a store, interact with products, and eventually will modify both retailers' and customers' understanding of the conventional sensory experience and overall perception of retail space. Emulating algorithms like Netflix's recommendation engine, which uses viewing history to suggest new films, retailers such as China's Hema hope to create targeted shopping suggestions for customers. In Hema stores, in-store purchases can be made through a mobile app; this generates a purchase history that eventually can be used to pre-populate suggested goods for an individual consumer. In addition to mining their data, these technologies try to better engage the consumer. By using information about realtime consumer interactions, sellers work to change existing products and develop new ones. The capacity of these technologies to influence sales might redefine the interface of shopping technology.

Augmented shopping can also facilitate detailed information about the products on sale. The 2015 Milan Expo featured an experiment by architect Carlo Ratti, with supermarket chain COOP Italia, that sought to determine if immediate access to digital information about food would affect the way consumers behaved. The "Future Food District" pavilion provided a functioning supermarket with 1,500 items on display. Digital mirrors presented background information: where the food came from, nutritional values, and manufacturing. According to Carlo Ratti: "Today, this information reaches the consumer in a fragmented way, but in the near future, we will be able to discover everything there is to know about the apple we are looking at: the tree it grew on, the $\mathrm{CO} 2$ it produced, the chemical treatments it received, and its journey to the supermarket shelf." In the words of the project leader: "It is like a return to the old marketplace, where producers and consumers of food saw each other and had actual interactions." 14

The hybrid marketplace is not only encouraging a one-way move from physical to online space; it also encourages online retailers to branch into physical space. Retailers do not see physical and online spaces as competing with one another, but rather as complimentary areas to be exploited. Amazon's acquisition of Whole Foods can provide an example of an online giant expanding into physical space.

\section{THE DIGITALIZATION OF CASHIERS AND SHOPPING ASSISTANTS}

Amazon and Walmart, two titans of retail, are experimenting with prototype stores that could, through automation and digitization, render in-store human employees unnecessary. Attempting to keep up with competitors, Walmart recently filed patents that we can read as predicting the future of the shopping experience. In August 2017, Walmart filed a patent to create a system of assistant drones to check prices and find products for shoppers. Another patent would equip shopping carts with sensors to report on their contents and their location. Walmart has also investigated using cameras and electrical transmitters to monitor shelves, ensuring they remain stocked with products. ${ }^{15}$

Amazon's first physical grocery store, "Amazon Go," is located in Seattle. To shop at the store, costumers need to download the Amazon Go app and scan their phones at the entry sensors. When finished, instead of waiting in line and interacting with a cashier, or cursing at automated checkout stations, shoppers can simply leave the store. Their purchases will be automatically deducted from their Amazon accounts, Amazon Go is checkout-free. This degree of fluidity and convenience is achieved at the expense of absolute surveillance (excluding facial recognition technology). Multiple cameras located on shelves and above aisles survey costumers while they shop. Additional weight sensors in the shelves track when products are lifted. The combination of these monitoring systems allows Amazon to accurately bill its costumers. Amazon Go is designed for speed, and cost efficiency. Amazon calls it "just walk out" technology. ${ }^{16}$ This technology could significantly reduce labor costs if this initial test is promising, though adopting the technology on a large scale might not be affordable yet. ${ }^{17}$ Human workers may be cheaper than Al for now, but as technology advances, the situation could look very different.

\section{STARTUPS AND THE DEMAND FOR ALTERNATIVE GROCERY FORMATS}

In recent years, a proliferation of startups are using technology to address some of the deficiencies in the "last mile" food supply chain with an emphasis on convenience. Instacart, is among the most popular grocery delivery app. For a percentage of the total sale, Instacart employs attendants who shop based on received online orders and deliver food purchases in an hour or two. The service is popular enough to have dedicated checkout lines in certain Whole Foods stores ${ }^{18}$ Corporate supermarkets understand the criticality of food delivery, but the challenges involved in transporting food in urban areas with high traffic difficult the adoption of online shopping. A 2014 study showed that up to 43 billion pounds of food were lost during transit due to mold or inadequate refrigeration. ${ }^{19}$ While online grocery shopping - paired with delivery services - could alleviate food desserts, the additional cost of packaging and transportation defies its affordability in the areas where it is most needed.

Startups are also testing alternative formats of food consumption at a faster pace than large established companies. Services such as Blue Apron, Hello Fresh, and Peach Dish that provide meal kits including a recipe and its required ingredients are reaching digital consumers. Fresh meal shipping plans have captured the curiosity of the new consumer palate. The young consumers who use and enjoy these services will most likely continue to use them as they age, passing their 


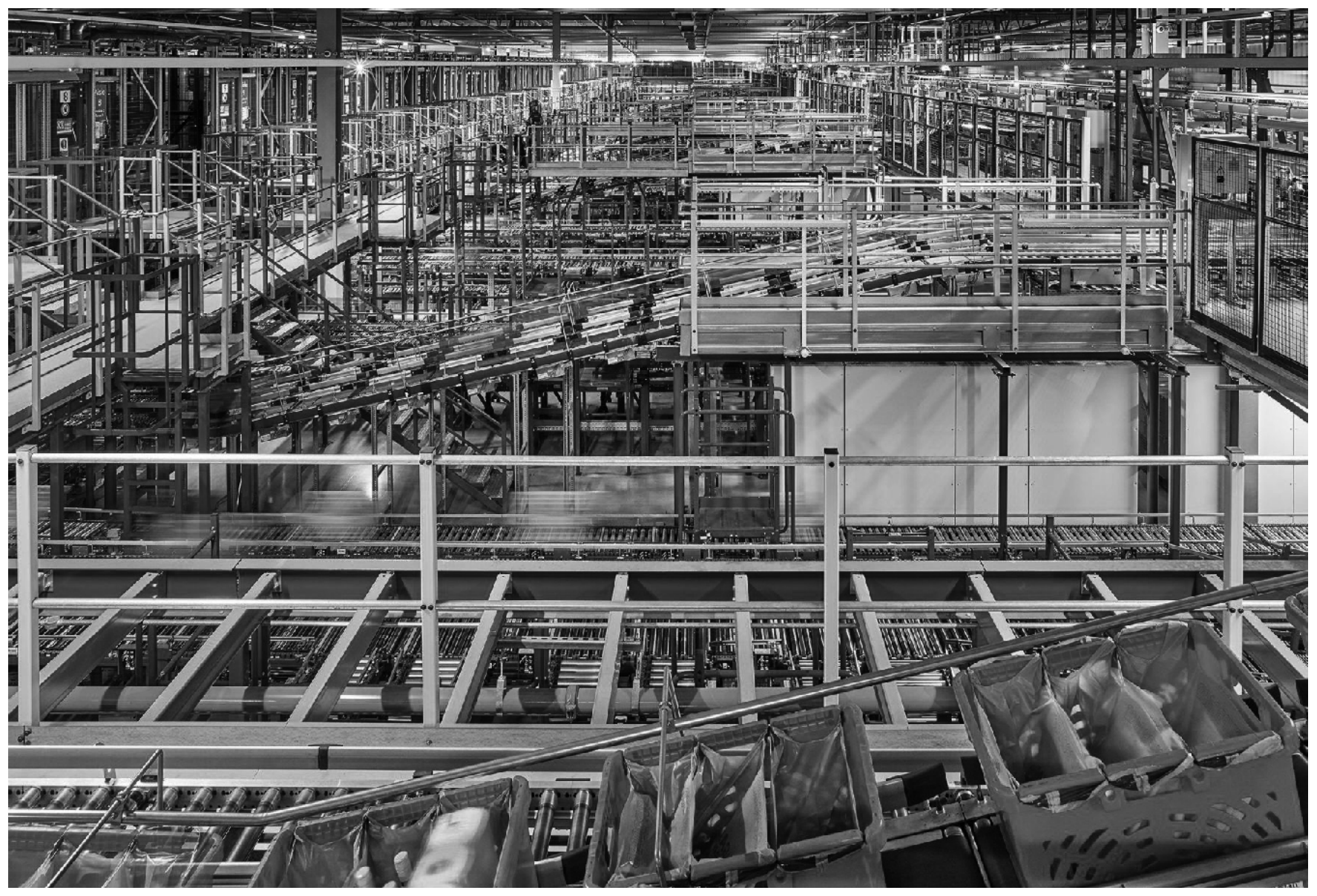

Figure 2: Ocado's Robot Warehouse by Greg White. Courtesy of Greg White.

habits down to new generations. ${ }^{20}$ This kind of alternative forms of food consumption at first challenge the industry, which eventually, adopts the same practices. For example, after Blue Apron's success, Amazon started offering their own meal kits, reducing Blue Apron's delivery time, and providing more food options. If recipe meal boxes become increasingly popular supermarkets could lose a significant consumer base. ${ }^{21}$

\section{DANGER OF EXTINCTION}

Alternative models of food distribution are starting to threaten the relevance of the supermarket. Is the supermarket space potentially obsolete? The UK "online supermarket" Ocado might be an example of how retailers could eliminate the physical supermarket entirely, as its multiple warehouses offer home delivery only. "Ocado is not primarily a retailer. Ocado is a technology company and creator of the Ocado Smart Platform, a hardware, software, logistics, robotics and Al system, that automates the picking and packing of individual grocery orders in massive warehouses." ${ }^{22}$ While it trails Amazon in items delivered, Ocado claims its warehouses are more automated than the online giant. Using a network of automated machines, conveyor belts, and cranes, all of it powered by artificial intelligence, Ocado quickly selects and delivers items to waiting trucks. Its systems continuously monitor conditions and collect data in a constant drive for efficiency.

Alternately, some apps aim to eliminate the middle man and connect consumers directly with food producers. Farmingo's software creates a network of farmers and food producers and helps to make the supply chain less opaque. "Consumers can track a tomato like a FedEx package," says its founder ${ }^{23}$. Farmingo's decentralized retail model, using a network of pickup and distribution locations, aims to create a "farm to table" dining experience and resolve classic distribution problems. In doing so, they are also promoting transparency, local producers, responsible practices, and shorter supply chains in the food retail industry.

\section{A PHYSICAL REACTION}

With online shopping becoming increasingly popular and alternative food distribution models threatening conventional food stores, some niche retailers are progressively shifting their retail spaces into showroom formats. For example, Nespresso's showroom like stores, allow visitors to taste a variety of coffees and learn about coffee machines and accessories available for purchase. ${ }^{24}$ Food retailers are 


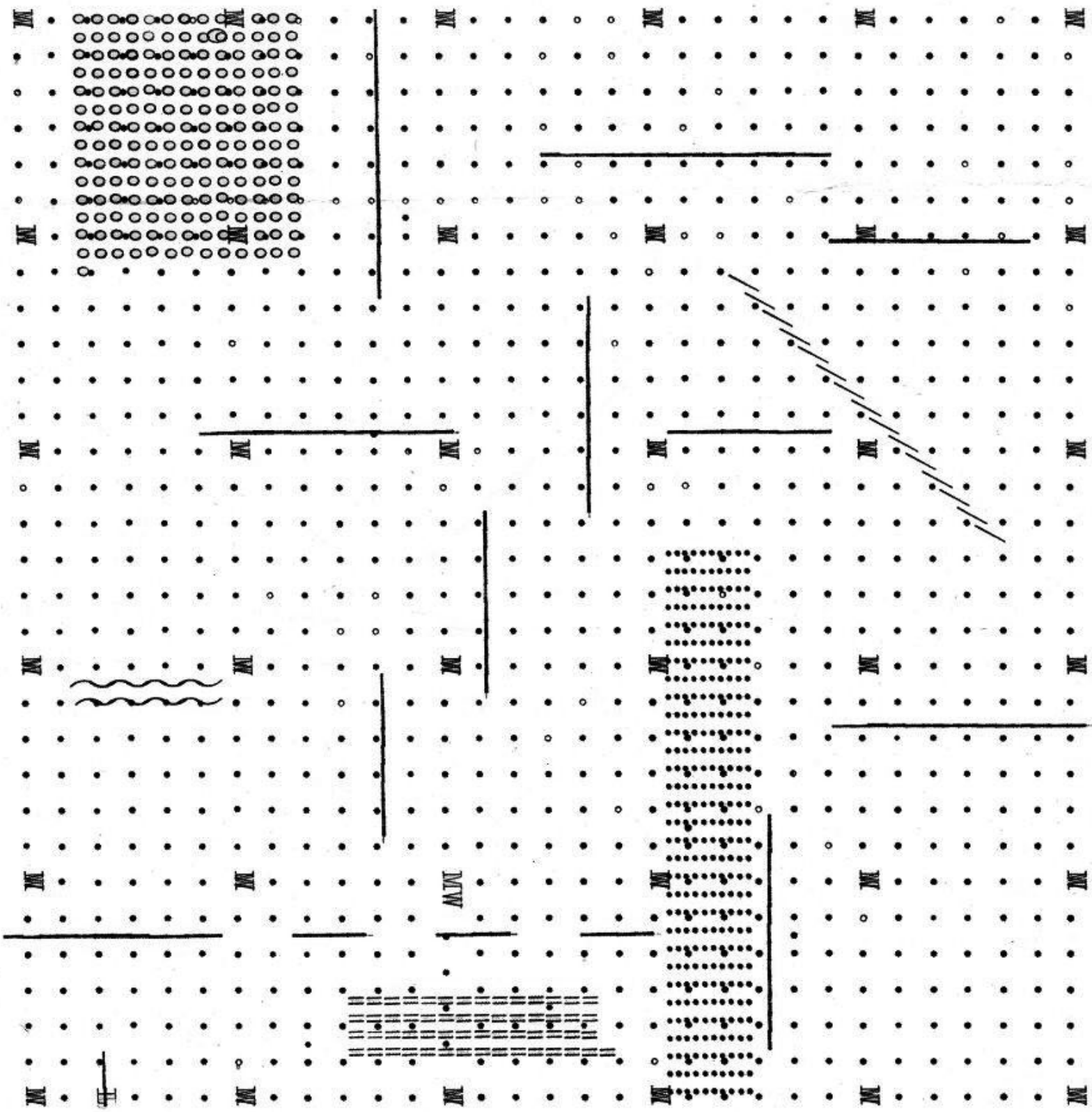

Figure 3: "Diagramma Abitativo Omogeneo" by Archizoom Associati. Courtesy of Andrea Branzi.

starting to offer unique and memorable experiences within highly designed boutique store environments. Overall, it does not seem that the brick and mortar supermarket apocalypse is close. Walmart has begun to create new and unique food experiences, hoping to lure customers into their stores and away from the competition. At their new Culinary Innovation Center, employees work on novel new foods such as Tropickles (pickles with fruit flavor) and grapes that taste like cotton candy. ${ }^{25}$ The sensory appeal of food to basic human appetites may always attract customers in search of a direct experience in the selection of produce and other food items. The tactile gratification of picking an apple and the olfactory pleasures of walking by the bakery section are powerful anchors of the traditional grocery experience. But given the pace of digital technologies, it is fair to assume that increasingly digitalized logistics will continue to transform and optimize the supermarket typology in the near future. The technologies operating today will undoubtedly change and even disappear 
in favor of new ones. The prospects of online shopping and new forms of delivery will further determine the evolution of the physical manifestation of the supermarket in the city. Online and offline will be further entangled in the new hybrid market place. Augmented shopping, automated in-store labor, streamlined delivery services, and further alterations of the supply chain enabled by the direct connection between producers and consumers will continue to transform, and maybe even eradicate, the supermarket as we know it today.

\section{ENDNOTES}

1. Andrea Branzi, No-Stop City, Archizoom Associati (Paris: HYX, Librarie de L'Architecture de la ville, 2006), 178.

2. Max Weber "The Nature of the City" in Classic Essays on the Culture of Cities, ed., Richard Sennet (Appleton-Century-Crofts, NJ: Prentice Hall, 1969).

3. Jesse LeCavalier, The Rule of Logistics: Walmart and the Architecture of Fulfillment (Minneapolis: University of Minnesota Press, 2016), Kindle edition.

4. "Supermarket Facts," Food Marketing Institute official website, accessed July 14, 2018, https://www.fmi.org/our-research/supermarket-facts.

5. LeCavalier, The Rule of Logistics.

6. Branzi, No-Stop City, 178.

7. Chung et al., Harvard Design School Guide to Shopping / Harvard Design School Project on the City 2 (Cologne: Taschen, 2002).

8. Chung et al., Harvard Design School Guide to Shopping

9. Recklessnutter, "Tesco Homeplus Virtual Subway Store in South Korea," YouTube video, 2:30, June 24, 2011, https://www.youtube.com/ watch?v=fGaVFRzTTP4.

10. Louise Driscoll, "Tesco Trials Virtual Grocery Shopping at Gatwick Airport," Airline Trends, August 2012, http://www.airlinetrends.com/2012/08/18/ tesco-virtual-grocery-gatwick-airport/.

11. Betsy Isaacson, "Yihaodian, Chinese E-Grocer, to Open Augmented Reality Markets Where Users Shop with Phones," Huffington Post, October 18, 2012, https://www.huffingtonpost.com/2012/10/17/chinese-e-grocer-yihaodianaugmented-reality_n_1975440.html.

12. Eric Jaffe, "The Grocery Store of the Future?," CITYLAB, February 23, 2012, https://www.citylab.com/transportation/2012/02/ 23, 2012, https://www.citylab.
grocery-store-future/1306/.

13. Sabrina Korber, "Retail's 'Beacon' of Hope: Shopping that's Personal," CNBC May 26, 2015, https://www.cnbc.com/2015/05/26/retails-newest-brick-andmortar-bet.html.

14. Amy Frearson, "Carlo Ratti Creates a Digital Supermarket at the Milan Expo 2015,"Dezeen, May 1, 2015, https://www.dezeen.com/2015/05/01/ carlo-ratti-digital-supermarket-milan-expo-2015-mit-coop-italia/.

15. Eleanor Gibson, "Walmart Files Patent for Drone Shopping Assistants," Dezeen, March 27, 2018, https://www.dezeen.com/2018/03/27/ walmart-
patent-drone-shopping-assistant-robot-wearable-technology/.

16. Laura Bliss, "Amazon Go Might Kill More than Just Supermarkets," CITYLAB March 14, 2018, https://www.citylab.com/life/2018/03/the-unbearable-sadness-of-amazon-go/555254/; Mat Burges, "The Technology Behind Amazon's
Surveillance-Heavy Go Store," Wired, January 22, 2018, https://www.wired. co.uk/article/amazon-go-seattle-uk-store-how-does-work.

17. Bliss, "Amazon Go Might Kill More than Just Supermarkets;" Burges, "The Technology Behind Amazon's Surveillance-Heavy Go Store."

18. Courtney Balestier, "The Supermarket Must Die. App-Fueled Services Can Kill It," WIRED, April 14, 2016, https://www.wired.com/2016/04/ supermarket-must-die-app-fueled-services-can-kill/.

19. Balestier, "The Supermarket Must Die."

20. Jiao Junfeng, "Your Neighbourhood Grocery Store is Changing," UT News, September 6, 2017, https://news.utexas.edu/2017/09/06/ your-neighborhood-grocery-store-is-changing/.

21. Junfeng, "Your Neighbourhood Grocery Store is Changing."

22. Joe Skorupa, "Ocado: The Tesla of Grocery," Retail Info Systems blog, July 9 , 2018. https://risnews.com/ocado-tesla-grocery.

23. Balestier, "The Supermarket Must Die."
24. Rebecca Smithers, "Nespresso to Open First UK Café in London," The Guardian, March 23, 2016, https://www.theguardian.com/business/2016/ $\mathrm{mar} / 23 /$ nespresso-open-first-uk-cafe-london.

25. Kenny Malone and Julia Dewitt, "Walmart's Pickle," NPR's "Planet Money" podcast, Episode 806, 18:00, November 17, 2017, https://www.npr.org/ sections/money/2017/11/17/564956657/episode-806-walmarts-pickleCongoleum-nairnlnc.FineFloorsAndWalls1960. 